\title{
ORIGEM E MOTIVAÇÕES DAS CAMINHADAS NA NATUREZA NO TERRITÓRIO VALE DO IVAÍ - PARANÁ
}

\section{ORIGIN AND MOTIVATIONS OF NATURE WALKINGS IN \\ IVAÍ VALLEY TERRITORY, PARANÁ - BRAZIL}

\author{
Clarice Bastarz \\ Universidade Federal de Santa Maria - Santa Maria - RS - Brasil \\ Marcelino de Souza \\ Universidade Federal do Rio Grande do Sul - Porto Alegre - RS - Brasil
}

\begin{abstract}
Resumo: As Caminhadas na Natureza configuram-se numa modalidade de turismo rural e propõem que comunidades rurais organizem circuitos de caminhada e vendam produtos e serviços a caminhantes oriundos de centros urbanos. O estudo pretende analisar a origem do projeto Caminhadas na Natureza, adotando o recorte geográfico do Território Vale do Ivaí, Estado do Paraná. Nesta análise foram observados o processo de desenvolvimento do projeto e as motivações que conduziram 42 atores a se envolver nas caminhadas, entre eles, agricultores, caminhantes e organizadores. Por meio de entrevistas semiestruturadas, observou-se que o projeto surgiu de uma organização social independente, mas foi fortemente impulsionado por diversas ações de políticas públicas, principalmente do Ministério do Desenvolvimento Agrário - MDA e da Empresa de Assistência Técnica e Extensão Rural - EMATER Paraná. As motivações que levaram os atores a se engajarem no projeto pertencem principalmente à dimensão social, seguida pela dimensão de prestígio e econômica.
\end{abstract}

Palavras-chave: Caminhadas na Natureza. Território Vale do Ivaí. Políticas públicas. Motivações.

Abstract: Nature Walkings constitute in a type of rural tourism and propose that rural communities organize walkings circuits and sell products and services to walkers coming from urban centers. The study aims to analyze the origin of the project Nature Walkings, adopting the geographical cut of the Ivaí Valley Territory, in state of Paraná. This analysis observed the development process of the project and the motivations that led 42 actors to engage on it (farmers, walkers and organizers). Through semistructured interviews, it was observed that the project borned of an independent social organization, but was strongly driven by various actions of public policies, particularly by MDA and EMATER Paraná. The motivations that led the actors to engage in the 
project belong mainly to the social dimension, then the dimension of prestige and economic.

Keywords: Nature Walkings. Ivaí Valley Territory. Public policy. Motivations.

\section{Introdução}

A temática do desenvolvimento rural tem sido abordada nos âmbitos acadêmico e político internacional nas últimas décadas, sobretudo a partir dos anos 1990. As mudanças sociais, econômicas, culturais e ambientais provocadas pelo processo de modernização da agricultura ainda são discutidas, pois este modelo de desenvolvimento, mais ou menos acelerado, a depender da região, não conseguiu beneficiar a todos. Alteração na estrutura fundiária, concentração de renda, estrangeirização da propriedade da terra, êxodo, envelhecimento da população rural, pressão ambiental são alguns efeitos da modernização da agricultura e originaram mudanças significativas no comportamento, racionalidade, organização social e atividades econômicas desenvolvidas pelos agricultores.

O cerceamento da agricultura tradicional, constatado quando seu desempenho positivo indispensável não consegue mais garantir a subsistência das famílias, faz com que os agricultores familiares criem inovações, estratégias e atividades econômicas alternativas, de caráter agrícola ou não agrícola, na tentativa de resistir.

$\mathrm{Na}$ perspectiva da multifuncionalidade, na qual este trabalho se insere, o espaço rural é reconhecido para além de sua função primária de produção de alimentos e matérias-primas. Ele desempenha múltiplas funções, tornando-se responsável também pela conservação dos recursos naturais, preservação do patrimônio cultural, atividades de lazer e, ainda, pela reprodução socioeconômica das famílias rurais (WANDERLEY, 2009). Do fenômeno da diversificação econômica das propriedades e da revalorização das áreas rurais emerge o turismo rural, como uma entre tantas outras possíveis alternativas encontradas pelos agricultores (KAGEYAMA, 2008; WANDERLEY, 2009).

Levando também em consideração o ponto de vista dos turistas, para os quais o espaço de referência é a cidade, as transformações sociais conduziram a um aumento do período de não trabalho, em que 
o lazer (ou inatividade), desde o seminal estudo de Veblen (1994) ${ }^{1}$, é analisado como um signo de distinção, inerente às classes sociais dominantes. Dessa linha, surgem as ideias do "direito ao lazer" e do "lazer compensatório", em que as férias e, por consequência, o turismo estão associados à saúde e ao bem-estar (STEIL, 2002).

Adotando o recorte geográfico do Território Vale do Ivaí, no Estado do Paraná, o estudo tem o objetivo de analisar qual foi a origem e as motivações do projeto Caminhadas na Natureza. Se faz importante esclarecer que o termo "origem" abrange o princípio do projeto, desde sua idealização até os dias atuais, bem como as motivações que conduziram os atores (agricultores, caminhantes e organizadores) a se envolver no projeto das caminhadas.

Impulsionado por uma política pública de desenvolvimento rural, o projeto Caminhadas na Natureza ocorre no Território do Vale do Ivaí como uma modalidade de turismo rural, em que um número considerável de participantes tem gerado um fluxo turístico regional importante. Esse projeto prevê que os agricultores das comunidades rurais anfitriãs, apoiados pelo Estado, realizem eventos de caminhadas, oferecendo aos turistas serviços de alimentação (café-da-manhã e almoço), bem como a venda direta de produtos locais (alimentos in natura, flores, produtos da agroindústria familiar, panifícios, artesanatos, entre outros). Esse modelo de caminhadas possui uma metodologia internacional, orientada pela Federação Internacional de Esportes Populares (IVV)2

\section{Caminhadas e turismo rural}

\footnotetext{
1 O livro "The Theory of the Leisure Class", publicado em 1889, é o primeiro trabalho das Ciências Sociais sobre o turismo, de acordo com STEIL (2002). Thorstein Veblen aborda o lazer no processo de constituição das classes sociais, relacionando-o ao turismo. Esta abordagem, nas Ciências Sociais, seria recorrente em estudos posteriores, principalmente a partir da segunda metade do século XX. É considerada um clássico na área.

2Internationaler Volkssportverband, o IVV, é uma federação internacional de esportes populares. Promovem eventos em que se realizam atividades físicas não competitivas em ambientes naturais, envolvendo participantes de todas as idades e estratos sociais. Possuem associações continentais na Europa, Ásia e Américas, com membros filiados em 50 países. Realizam 7.500 eventos de esportes populares, os quais envolvem a participação de 10 milhões de pessoas por ano. A instituição brasileira membro do IVV é a Anda Brasil, que atua como idealizadora e coordenadora do Projeto Caminhadas na Natureza (FAWCET, 2015).
} 
Muito mudou no turismo rural com a modernidade. Com a consolidação do turismo moderno e de massa no século XX, a partir dos anos 1970 e 1980, surgiu o "conceito emergente de turismo rural" e se criou uma nova forma de turismo quase como um acidente (Lane, 2014, p. 18). Um tipo de turismo baseado na procura por uma experiência turística muito diferente do que até então existia no turismo de massa: os resorts ${ }^{3}$. Uma experiência sem multidões, em contato com a natureza, com a paisagem agrária, com a população rural e com variedades de atrações graduadas entre a tradição e a aventura.

Lane (2014) afirma que esse tipo de turismo surgiu com o apelo da "moda" aos lugares naturais e do aumento das facilidades de acesso e dos níveis de renda e educação. Ao contrário dos resorts, o que chama a atenção é que a oferta do turismo rural moderno não surgiu do setor privado, mas de "vários pequenos agricultores e empreendedores rurais interessados em 'sobreviver' face aos retornos decrescentes da agricultura e de outras pequenas empresas rurais" (LANE, 2014, p.18).

Considera-se, para o presente estudo, que a grande contribuição de Rodrigues (2000) tenha sido - além de iniciar um debate visando dar base a uma urgente e mais adequada regulação da atividade, diminuição de danos causados pela atividade turística e maximização de seus benefícios - trazer à luz a discussão sobre o turismo rural como um turismo híbrido. Para Rodrigues, o turismo rural pode estar associado a outros segmentos de turismo, focando sua argumentação no ecoturismo. Ela diz que "quando o hibridismo é muito acentuado, já propusemos a denominação de turismo eco-rural" (RODRIGUES, 2000, p. 55).

Esse longo e complexo debate, que dura até os dias atuais, contribuiu para o avanço de algumas questões, porém Tulik (2010) acredita que há ainda muito a ser feito quanto a definir e tipificar o turismo rural. Contudo, não é objetivo deste artigo adentrar nesse debate. O breve resgate e apresentação do mesmo serve para pautar o argumento de que a profusão de variedades de turismo rural que

\footnotetext{
3 Para Lane (2014) os resorts tiveram (e ainda têm) um papel muito importante para o turismo de massa moderno, do ponto de vista operacional. Os resorts cresceram visando proporcionar a satisfação total das necessidades dos turistas num mesmo local: atrações, entretenimento, acomodações, alimentação e paisagem.
} 
existem no Brasil, demonstram a complexidade deste fenômeno desde seu surgimento, quase como um acidente, como disse Lane (2014). Fato que tende a complicar diante de transformações cada vez mais aceleradas e descompassadas na sociedade, em diferentes ritmos, a depender da região. $O$ importante é manter o olhar atento a essas transformações e aceitar novas modalidades híbridas de turismo rural que surgem, como é o caso das Caminhadas na Natureza.

As caminhadas, na perspectiva da teoria do turismo, são consideradas atividades ligadas à natureza e ao segmento de ecoturismo ou turismo de aventura (ABETA, 2015). Na Europa, conforme Tulik (2003), o turismo rural possui sentido amplo e inclui o turismo de natureza, que pode ser considerado como o ecoturismo em áreas rurais. Para Ezequiel e Carvalho (2014, p. 85), o turismo de natureza em Portugal, ainda que "instintivamente associado às áreas protegidas", estende-se também aos espaços rurais em todo o território nacional e está ligado à animação e prática de esportes de natureza.

De acordo com Ezequiel e Carvalho (2014), o pedestrianismo (como é chamado o ato/esporte de caminhar em Portugal), no segmento turismo de natureza, é classificado como uma atividade soft, com experiências ao ar livre de baixa intensidade. Outra classificação são as atividades hard, sendo a prática de desportos (rafting, escalada, rapel, etc.) ou atividades que exigem concentração e conhecimento prévio dos turistas (observação de pássaros). A classificação hard se assemelha ao segmento turismo de aventura, termo que se utiliza no Brasil. $O$ pedestrianismo é, para os autores, uma importante estratégia para o desenvolvimento dos espaços rurais portugueses "com irrevogáveis reflexos para a melhoria da qualidade de vida das comunidades receptoras" e satisfação dos visitantes (EZEQUIEL, CARVALHO, 2014, p. 82).

$\mathrm{Na}$ literatura científica, há poucos trabalhos a respeito de caminhadas na perspectiva do turismo e desenvolvimento rural. A dificuldade em encontrar trabalhos na temática foi observada por Kouchner e Lyard (2001) quando redigiram o documento intitulado "Desenvolvendo caminhadas em áreas rurais"4, inerente ao Programa

4 Tradução nossa. 
LEADER II5 (Relações entre Ações de Desenvolvimento Rural), elaborado pela Direção Geral de Agricultura da Comissão Europeia. Os autores afirmam ainda que as caminhadas foram por muito tempo subestimadas e ignoradas, mas que hoje (em 2001) são percebidas como a maneira ideal de desenvolvimento do turismo local. O documento não tem caráter científico. Apesar de apresentar dados sobre perfil de caminhantes europeus e suas motivações, não há nenhuma referência bibliográfica que indique as fontes. Ele foi redigido como um guia para o planejamento e implementação de um projeto de caminhadas, ou seja, a linguagem é destinada aos agricultores e moradores de comunidades rurais, visando a estimular o desenvolvimento de atividades turísticas destinadas ao público das caminhadas.

Embora o documento de Kouchner e Lyard (2001) não tenha caráter científico, sua existência é relevante pois demostra que as caminhadas foram pensadas a atuar como estratégia de desenvolvimento rural e turismo, através do apoio a iniciativas locais em toda a União Europeia. O que corrobora com o debate acadêmico internacional sobre desenvolvimento rural, multifuncionalidade e diversificação econômica.

O modelo paranaense de Caminhadas na Natureza, que acontece no Vale do Ivaí, foi adaptado do modelo europeu, que já existia antes de ser descrito por Kouchner e Lyard (2001). Retomando a ideia de turismo híbrido de Rodrigues (2000), o envolvimento de agricultores, relação com a paisagem rural e a agricultura, imersão num contexto de revalorização e desenvolvimento são critérios que dão argumentos para afirmar que as caminhadas são uma modalidade de turismo rural, embora haja apelos culturais, ecoturísticos, desportivos, de lazer, gastronômicos, etc.

\section{Procedimentos metodológicos}

Para compreender a origem do projeto Caminhadas na Natureza no Território Vale do Ivaí, foi realizado um estudo de caso e pesquisa de

5 O Programa LEADER, que em português significa Relações entre Ações de Desenvolvimento Rural, é parte integrante da Política de Desenvolvimento Rural, componente da Política Agrícola Comum (PAC) da União Europeia. O objetivo do LEADER era aumentar o potencial de desenvolvimento das áreas rurais, baseando-se em iniciativas locais, promovendo o saber-fazer no domínio do desenvolvimento local e divulgando esse saber-fazer a outras zonas rurais. 
caráter qualitativo, em que os dados foram obtidos por meio de pesquisa documental e roteiro de entrevistas semiestruturado.

Para a análise do processo de implantação do projeto das caminhadas no Vale, as entrevistas foram realizadas com informanteschave. Foi estabelecido que esses informantes seriam pessoas que protagonizaram e que estivessem diretamente relacionadas ao processo desde antes da implantação das caminhadas ao território. Os informantes identificados foram: $\mathrm{ICl}$ - Presidente da Anda Brasil (instituição que deu início às caminhadas do modelo IVV no Brasil); IC2 O primeiro coordenador do projeto no Paraná e; IC3 - A coordenadora do projeto no Território Vale do Ivaí.

A preocupação foi compreender como o projeto surgiu, tornou-se política pública e como foi absorvido pelo Território. Para tal, foi realizada análise de conteúdo dos dados coletados em entrevistas e nas fontes documentais que foram pesquisadas. As categorias analisadas foram: Período de formação - em que momento o projeto surgiu e formalizou-se; Arranjo institucional - quais instituições eram e são atuantes; Governança - forma de organização dos atores para gerir o projeto;

Os informantes foram entrevistados em duas etapas. Em março de 2015, durante a primeira pesquisa de campo, foi entrevistada IC3. Por sua vez, ICl e IC2 foram entrevistados durante o Encontro Nacional da Anda Brasil, realizado em Itabirito (MG), em outubro de 2015.

Tendo em vista que não se conhecia o número exato de atores que participavam das Caminhadas na Natureza, foi utilizada a técnica bola de neve. Essa técnica, conforme Souza e Quandt (2008), é utilizada principalmente quando a população a ser pesquisada não é conhecida. A técnica inicia com a seleção de um ator ou conjunto de atores a partir dos quais os demais entrevistados são rastreados. Assim, a amostra dos atores entrevistados foi dada a partir da identificação inicial de atores, que, por sua vez, indicaram outros atores a serem entrevistados.

No caso desta pesquisa, o primeiro ator entrevistado e que indicou os demais atores foi IC3, Coordenadora Estadual do Projeto Caminhadas na Natureza do Paraná. IC3 é uma protagonista do projeto, esteve e continua atuando desde o início das caminhadas no Vale do Ivaí. 
Foi estabelecido que esse primeiro ator deveria indicar outros atores com os quais se relaciona a fim de participar das caminhadas na natureza, podendo ser agricultores caminhantes ou organizadores. Os atores indicados deveriam ser entrevistados e, por sua vez, indicariam outros atores a serem entrevistados e assim por diante, conforme propõe a técnica bola de neve. Nesse sentido, poderia haver reciprocidade de indicações, ou seja, o ator que indicou poderia ser também indicado. Não houve limites para o número de atores indicados, sendo a quantidade de indicações e a sua reciprocidade parte do resultado a ser analisado. As entrevistas foram do tipo semiestruturadas e a amostragem foi do tipo intencional não probabilística, dada através da técnica bola de neve, resultando em 42 pessoas. Foi realizada coleta de dados em três comunidades rurais do Vale do Ivaí, em março, maio e outubro de 2015.

Para compreender as motivações que conduzem os atores a se envolver no projeto Caminhadas na Natureza, foram entrevistadas 42 pessoas, sendo 13 agricultores, 12 caminhantes e 17 organizadores. 0 perfil socioeconômico dos entrevistados encontra-se detalhado na tabela 1.

Tabela 1. Perfil socioeconômico dos entrevistados

\begin{tabular}{lcccc}
\hline & Total & Caminhantes & Agricultores & Organizadores \\
\hline $\begin{array}{l}\text { Gênero } \\
\quad \text { Masculino }\end{array}$ & 25 & 7 & 7 & 11 \\
$\quad$ Feminino & 17 & 5 & 6 & 6 \\
\hline Idade & & & & \\
$\quad$ Até 20 & 2 & 0 & 0 & 0 \\
$21-30$ & 4 & 0 & 0 & 2 \\
$31-40$ & 15 & 2 & 1 & 1 \\
$41-50$ & 17 & 3 & 6 & 6 \\
$51-64$ & 4 & 7 & 3 & 7 \\
65 ou mais & & 0 & 3 & 1 \\
\hline Nível de Escolaridade & 1 & 0 & 1 & 0 \\
Sem escolaridade & 7 & 0 & 7 & 0 \\
Ensino Fundamental & 8 & 2 & 3 & 3 \\
Ensino Médio & 4 & 1 & 0 & 3 \\
Ensino Técnico & 8 & 2 & 0 & 6 \\
Ensino Superior & 14 & 7 & 2 & 5 \\
$\quad$ Pós-graduação & & & & \\
\hline Renda Familar (Rs) & & & & \\
\hline
\end{tabular}

Renda Familiar (R\$)6

${ }^{6}$ A renda familiar não foi solicitada aos organizadores e agricultores, apenas aos caminhantes. 


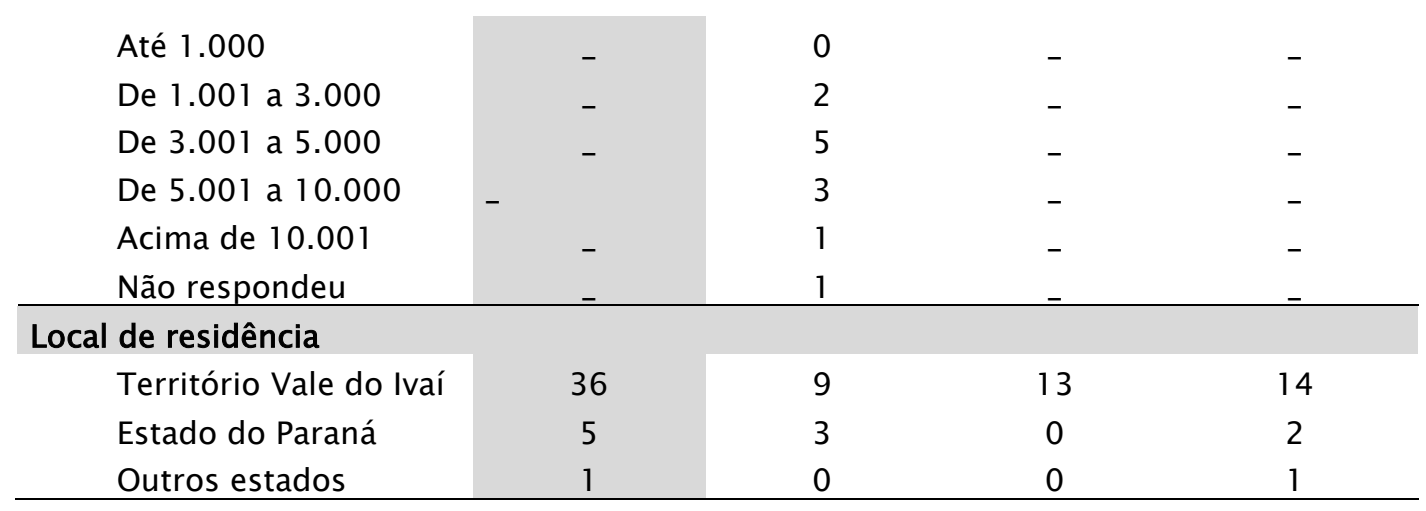

Fonte: elaborado pelos autores.

No sentido de classificar as motivações e a satisfação dos atores envolvidos nas Caminhadas na Natureza no Território Vale do Ivaí (agricultores, caminhantes e organizadores), utilizou-se as quatro dimensões para a classificação de McIntoch, Goeldner e Ritchie (1995), quais sejam: física, cultural, interpessoal e status e prestígio. Ademais, ao revisar sólidas discussões a respeito das motivações para caminhar e motivações para o turismo rural, percebeu-se a necessidade de adicionar mais duas dimensões no sentido de enriquecer a análise, sendo a emocional (nostalgia) e ruralidade (características intrínsecas ao rural). Além disso, para incluir motivações de agricultores, incluiu-se a dimensão econômica.

\section{Características do Território Vale do Ivaí}

Localizado na região Centro-Norte do Estado do Paraná, o Território Vale do Ivaí foi assim denominado pelo estudo de autoria de pesquisadores do Instituto Agronômico do Paraná - IAPAR, publicado em 2002 (FUENTES LLANILLO et al, 2002). Segundo os autores, é uma região de ocupação recente, do fim do Ciclo do Café nos anos 1960 e 1970, que sofreu estagnação e processo de pecuarização extensiva a partir dos anos 1980, exceto nos municípios integrados à agricultura moderna de grãos. Essa região apresenta parte significativa das áreas ocupadas por cultivo de café e lavouras permanentes, pecuária bovina extensiva, pastagens plantadas e poucos remanescentes de mata nativa. Foi constatada também a baixa utilização de tecnologia agropecuária, predominando o caráter familiar nas explorações agrícolas.

Em 2013, foi publicada no Diário Oficial da União - DOU a Resolução 94 do Conselho Nacional do Desenvolvimento Rural 
Sustentável - CONDRAF, ligado ao MDA, que inclui novos territórios rurais no Programa Nacional de Desenvolvimento Sustentável de Territórios Rurais - PRONAT. Entre eles, consta o Território Vale do Ivaí, que é formado por 26 municípios: Apucarana, Arapuã, Ariranha do Ivaí, Barboza Ferraz, Bom Sucesso, Borrazópolis, Califórnia, Cambira, Corumbataí do Sul, Cruzmaltina, Faxinal, Godoy Moreira, Grandes Rios, Ivaiporã, Jandaia do Sul, Jardim Alegre, Kaloré, Lidianopólis, Lunardelli, Marilândia do Sul, Marumbi, Mauá da Serra, Novo Itacolomi, Rio Bom, São João do Ivaí e São Pedro do Ivaí, conforme apresentado na Figura 1.

O Vale do Ivaí possui uma população total de 330.695 habitantes e grau de urbanização médio de $81,2 \%$. Os dois maiores municípios em população da região são: Apucarana com 120.919 habitantes (36\% da população do Vale), sendo quase quatro vezes maior do que o segundo maior município em população, Ivaiporã, com 31.816 habitantes. Notase também uma concentração da economia regional no Município de Apucarana, que tem sua relevância como polo produtivo regional. Apucarana apresentou sozinho 40,14\% do PIB do território em 2010 (IBGE, 2015). 
Figura 1. Mapa de localização do Território Vale do Ivaí e seus municípios

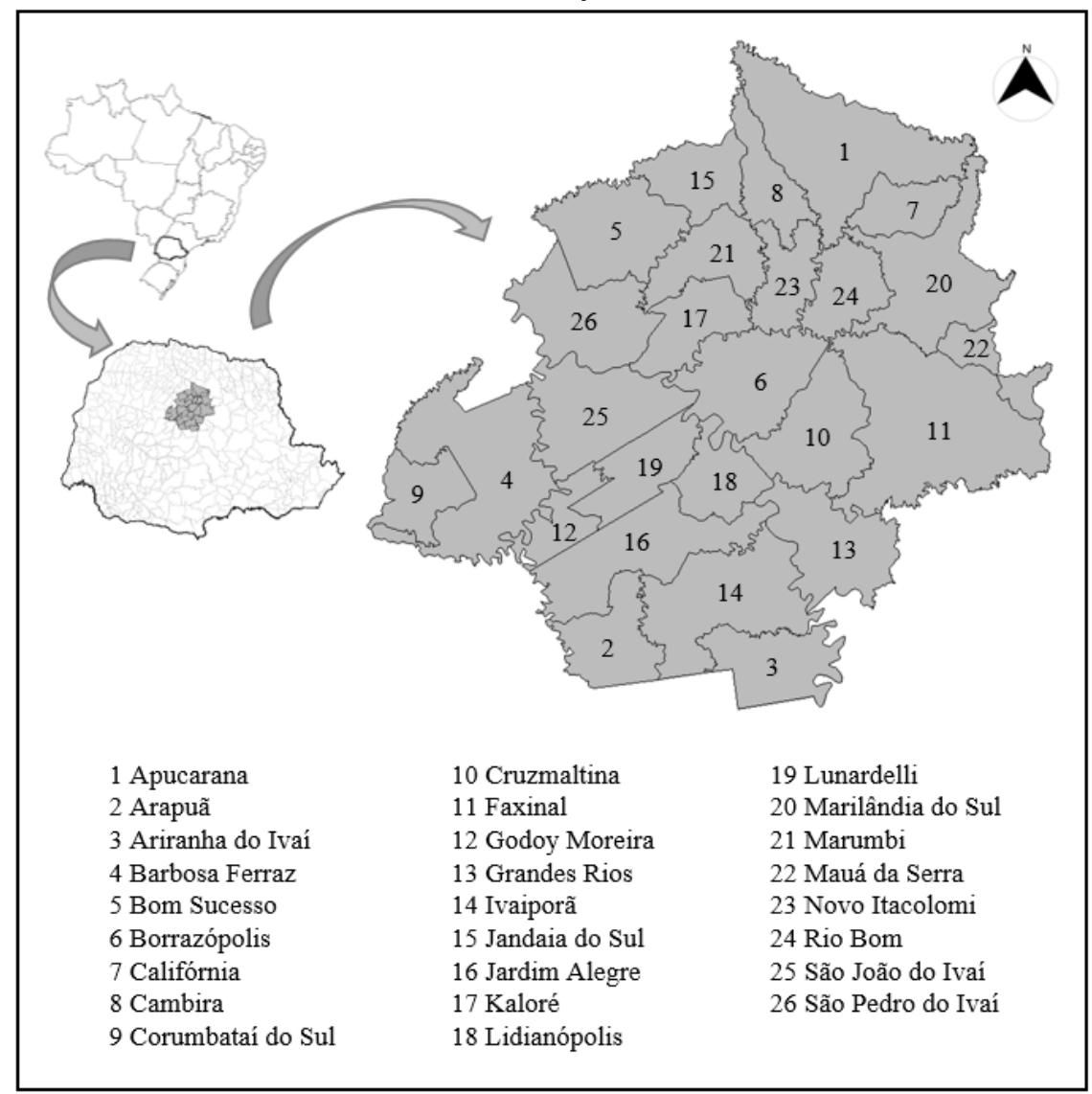

Fonte: elaborado pelos autores.

Em termos de desempenho socioeconômico, demonstrado pelo Índice de Desenvolvimento Humano - IDH dos 399 municípios paranaenses, Apucarana ocupa a $33^{a}$ posição no ranking e Jandaia do Sul a $37^{\mathrm{a}}$, com 0,748 e 0,747 pontos, respectivamente. Por outro lado, Mauá da Serra e Corumbataí do Sul ocupam posições bastante desfavoráveis, sendo a $356^{\text {a }}$ e a $373^{\text {a }}$ no ranking, com respectivos 0,652 e 0,638 pontos. A média do IDH dos municípios do Vale do Ivaí é 0,697 e todos os municípios do Vale estão abaixo do IDH médio paranaense, que é 0,749 pontos. Isto demonstra a fragilidade socioeconômica e vulnerabilidade social do território (IBGE, 2015).

\section{Início das Caminhadas na Natureza no Território Vale do Ivaí}

As caminhadas na natureza no espaço rural surgiram, de acordo com o IVV (2015), logo após a Segunda Guerra Mundial na Europa. O objetivo de caminhar no interior das províncias e na periferia das 
grandes cidades centrou-se em estimular as atividades comerciais destas regiões abaladas pela guerra. Desde então, os caminhantes começaram a organizar-se formalmente em clubes de caminhadas no sentido de formarem grupos de interação social. O IVV foi fundado em 1968 na Alemanha, sendo a Áustria, Liechtenstein e Suíça países cofundadores (IVV, 2015).

Com o crescimento da atividade turística e valorização dos patrimônios cultural e natural das localidades, as caminhadas começaram a ser utilizadas como fator de integração e inclusão social entre as populações regionais, caracterizando-se como uma atividade popular e democrática, sendo nomeada como um esporte popular (ANDA BRASIL, 2007). Os esportes populares promovidos pelo IVV não possuem caráter competitivo e, além da caminhada, o hiking (subida de montanha), o ciclismo e a natação são as principais categorias. Em 2014, ocorreram mais de 7.500 eventos de esportes populares, os quais compreenderam mais de 10 milhões de participações distribuídas por 50 países federados, segundo os números do IVV (2015).

Em nosso país, o desenvolvimento das caminhadas acontece desde os anos 1990, porém de maneira informal. Quem iniciou esse trabalho foi $I C 1$, fundador e atual presidente da Organização Não Governamental "Anda Brasil”. Engenheiro eletricista de formação, IC1 mudou-se para a área rural de Nova Friburgo, Rio de Janeiro, após residir três anos na Inglaterra exercendo a profissão. Já no Brasil, iniciou a criação de cabras e, para viabilizar sua produção, acreditava que deveria convencer seus vizinhos a também criar cabras, formando uma cadeia produtiva. Entretanto, ao participar de um curso da Queijaria Escola de Nova Friburgo, conheceu o técnico francês enviado pelo IRCOD - Instituto Regional de Cooperação e Desenvolvimento, JeanMarie Henry. O técnico fora enviado para contribuir com o processo de desenvolvimento da região e alertou para o potencial em turismo rural que o distrito possuía. Além de criação de cabras, os vizinhos do ICI (também de origem urbana) produziam bromélias, trutas, artesanatos, agricultura orgânica e também ofereciam serviço de massagem (shiatsu). Diante da diversidade de atividades agrícolas e não agrícolas, somando-se a localização estratégica de apenas $10 \mathrm{~km}$ da sede de Nova Friburgo, IC1 percebeu que o turismo rural poderia ser uma boa alternativa. 
Durante a entrevista, ICl não soube precisar o ano, mas no início dos anos 1990, após elaborar um primeiro projeto de turismo rural no modelo de organização social, conforme sugerido pelo IRCOD, ICl foi convidado a ir para Alsace (leste da França) conhecer como o turismo rural da região era desenvolvido. Nessa visita, $\mathrm{ICl}$ conheceu a Federação Francesa de Esportes Populares, filiada ao IVV, e a metodologia de organização de caminhadas. Entre voltar da França e organizar o primeiro circuito de caminhadas em seu distrito houve um intervalo de três anos. Entretanto, era um projeto de turismo rural, em que a caminhada era um componente a mais (um produto turístico).

Com a visibilidade adquirida pelo modelo de turismo rural e organização social independente implantado em Nova Friburgo, ICl foi convidado a ser consultor do Serviço Brasileiro de Apoio às Micro e Pequenas Empresas - SEBRAE em turismo rural e organização social e iniciou a difusão dos circuitos de caminhada pelos municípios vizinhos, já sob a alcunha de "Caminhadas na Natureza". Segundo $\mathrm{IC} 1$, já se visava a, nessa época, transformar essas ações em programa de estado.

Neste ínterim, houve mudança no governo federal e foram criados o Ministério do Turismo MTUR e o MDA, em 2003. Nos dois ministérios houve trabalhos no segmento de turismo rural. Por seu lado, o MTUR focou a política em ações para o fortalecimento dos segmentos de turismo, dentre eles o rural, em que a segmentação era parte de uma estratégia de marketing, visando o crescimento do turismo do Brasil. $O$ MDA, por outro lado, voltou sua política na direção da diversificação econômica de propriedades da agricultura familiar, na qual o turismo rural poderia ser uma alternativa de ocupação e complemento de renda para as famílias.

A pessoa designada para coordenar o turismo rural no MDA foi o IC2, oriundo da EMATER-PR. Após a passagem pelo MDA, IC2 retornou ao Paraná e exerceu cargo de assessoria técnica do Secretário de Estado da Agricultura e Abastecimento - SEAB-PR entre 2007 e 2010. Atualmente, IC2 é assessor técnico em meio ambiente do Ministério Público do Paraná.

Uma das ações do MDA, na época, era o treinamento de técnicos municipais da EMATER e prefeituras para o tema turismo rural, por meio de oficinas regionais. Para executar políticas públicas, outra ação desse Ministério foi criar uma rede de técnicos engajados em turismo rural na 
agricultura familiar que pudessem debater e operacionalizar projetos em âmbito local, a chamada REDE TRAF (Turismo Rural na Agricultura Familiar). Durante uma visita ao Estado do Rio de Janeiro, IC2 e IC1 se conheceram.

Em 2005, ICl organizou, em conjunto com o IVV e Federação Francesa de Esportes Populares, uma missão técnica em que foram convidados alguns interessados em conhecer os eventos de caminhadas na Europa, com o objetivo de compreender sua organização e dinâmica. Acompanhado de um grupo da região de Foz do Iguaçu - PR, IC2 foi um dos participantes dessa missão.

Por ser servidor público e ter atuado muitos anos na extensão rural, IC2 observou o projeto das caminhadas como uma possível política pública nacional de turismo rural, em que as caminhadas poderiam ser uma estratégia transversal para a promoção do desenvolvimento rural, com a inclusão dos agricultores familiares. Além disso, ao contrário da organização informal de $\mathrm{ICl}$, o MDA possuía meios de difundir o projeto em âmbito nacional, por meio, principalmente, do financiamento do treinamento dos técnicos da Rede TRAF, que iriam coordenar e operacionalizar os projetos em nível estadual e local.

Para legitimar e formalizar o apoio do MDA ao projeto das caminhadas, vislumbrou-se então a necessidade da criação de uma entidade que representasse as Caminhadas na Natureza. Conforme IC2, em 2006, para o credenciamento oficial dos circuitos de caminhadas brasileiras no IVV, foi necessária a criação da organização não governamental "Anda Brasil", com sede no interior do Estado do Rio de Janeiro, imbuída de organizar e cadastrar circuitos nacionais, realizar a interlocução dos estados com as entidades internacionais no sentido de qualificar e promover os roteiros e circuitos brasileiros (ANDA BRASIL, 2007).

O projeto cresceu em âmbito nacional devido ao apoio financeiro e institucional do MDA na capacitação de técnicos e lideranças de diversos estados do país em oficinas macrorregionais; da viabilização da participação da Anda Brasil no Salão de Turismo; de Missões Técnicas Internacionais; e da mobilização da Rede TRAF na formatação de 106 circuitos iniciais de caminhadas, lançados em 2007 (ANDA BRASIL, 2007). 
De acordo com a SEAB-PR (2008), a Secretaria Nacional da Agricultura Familiar do MDA - SAF/MDA, atribuiu ao projeto âmbito nacional através do treinamento de técnicos da Extensão Rural para a organização do turismo na agricultura familiar, fortalecendo iniciativas preexistentes e criando outras, incluindo-se os circuitos de caminhadas nas comunidades rurais.

No Paraná, o projeto das caminhadas se iniciou com a participação de técnicos da EMATER na I Oficina de Caminhadas, realizada ainda em 2005, em Casimiro de Abreu - PR. A realização dessa oficina foi possível com o apoio institucional e financeiro do MDA. Após essa primeira oficina, somando a vivência da missão técnica do grupo da região de Foz do Iguaçu, o Paraná realizou seu primeiro circuito de caminhada em 7 de setembro de 2005 em São Miguel do Iguaçu - PR. Contando com apoio da prefeitura e ampla divulgação, o evento contabilizou a participação de cerca de três mil pessoas.

Em 2007, IC2 retorna ao Paraná para assumir a assessoria técnica do Secretário de Estado da Agricultura e Abastecimento. Embora sua assessoria ultrapassasse o tema turismo rural, continuou coordenando as atividades na área, mas na esfera estadual. No Paraná, de acordo com a SEAB (2008), em 2007, a SEAB, em conjunto com a EMATER-PR, propuseram as caminhadas como política de estímulo ao desenvolvimento territorial sustentável e lançaram o Projeto "Caminhadas na Natureza no Paraná" como ação de incentivo e promoção do TRAF.

A participação do Vale do Ivaí iniciou em 2007, quando foi realizado, em Caxias do Sul - RS, um curso sobre "Manejo de Trilhas" para Agentes de Assistência Técnica e Extensão Rural - ATER da região Sul, uma parceria da SAF/MDA com a Escola de Agriturismo de Caxias do Sul. Com o apoio do MDA e EMATER-PR, um grupo de oito técnicos participou desse curso, entre eles IC3, a técnica do Escritório Regional de Ivaiporã.

IC3 é a terceira entrevistada para relatar o início das caminhadas no Vale do Ivaí, pois foi protagonista do desenvolvimento do projeto no território. IC3 é responsável pelo Projeto Caminhadas na Natureza desde o início na região de Ivaiporã. Desde 2012, é responsável pelo projeto em âmbito estadual e é Coordenadora Estadual de Turismo Rural da EMATER-PR. 
Nesse curso, IC3 conheceu IC1, que era um dos palestrantes. Segundo IC3:

Daí durante o curso de trilhas, o Violento, que era Presidente da Anda Brasil deu uma palestra de meia hora dizendo o que era uma caminhada. Daí aquilo me veio na cabeça, me deu um estralo, né? 'Poxa, mas isso na minha região seria muito bom para o pessoal conhecer'. Porque essa região sempre foi conhecida pelo baixo IDH, pela pobreza. As pessoas dizem: 'ah, lá é um lugar pobre, é não seio o que’. E isso me irritava. Nós somos um lugar pobre? Somos. Mas, aqui tem muitas coisas boas: pessoas, etnias, costumes... É um lugar lindo, tem uma geografia linda. Então aquilo me doía quando eu ouvia. Então, eu fiquei pensando nisso. (IC3, 61, Coordenadora Estadual de Turismo Rural da EMATER-PR).

$\mathrm{Na}$ palestra de IC1, IC3 imediatamente percebeu o potencial de sua região, que, embora pobre, possuía elementos estéticos e culturais impressos na paisagem que poderiam ser apropriados pelo turismo e poderiam mudar a percepção das pessoas sobre seu próprio lugar, valorizando-o.

IC3 relata ainda que durante esse curso em Caxias do Sul, IC2 Bueno anunciou a realização da II Oficina Nacional de Caminhadas na Natureza que ocorreria em setembro daquele ano em Curitiba - PR. Nesse evento, segundo a SEAB (2008), foram capacitados 40 técnicos municipais, oriundos de todas as regiões do estado, para planejar, organizar e executar circuitos de caminhada, conforme padrões internacionais estabelecidos pelo IVV.

Como técnica regional da EMATER, IC3 indicou três técnicas dos escritórios municipais para participar da II Oficina, que, segundo ela, já voltaram com dois circuitos idealizados. Esses dois circuitos fizeram parte do primeiro calendário de Caminhadas na Natureza no Paraná, lançado em 2008, com, inicialmente, 20 circuitos.

O primeiro circuito realizado na região de Ivaiporã ocorreu em Manoel Ribas7, no dia 21 de abril de 2008. O chamado "Circuito

7 O Território Vale do Ivaí é sobreposto por três regiões administrativas da EMATER: Apucarana, Campo Mourão e Ivaiporã. O Município de Manoel Ribas, escolhido como área de estudo para a pesquisa, não pertence ao Território Vale do Ivaí, mas pertence à região de Ivaiporã, onde a IC3 Zarpelon atua. Por ser a primeira experiência em caminhadas da região, julgou-se importante incluir o Município de Manoel Ribas na 
Jacutinga" reuniu 262 pessoas. De acordo com IC3, antes da realização desse primeiro circuito, "ninguém acreditava que alguém iria caminhar", mas, após a caminhada, ela recebeu diversas mensagens de caminhantes dizendo que gostaram e que queriam caminhar mais.

Com o retorno positivo por parte dos caminhantes, organizadores e agricultores, IC3 relata que contatou IC2 Bueno e solicitou a realização de uma Oficina Regional de Caminhadas. Essa oficina contou com a participação de 40 pessoas da região, sendo elas técnicos dos escritórios municipais da EMATER e técnicos das prefeituras da região de Ivaiporã. Logo após a oficina, ocorreu a caminhada no Município de Lunardelli - PR, da qual participaram 360 pessoas. A caminhada no circuito Santa Rita de Cássia foi realizada em 20 de julho de 2008.

IC3 afirma que, com a oficina regional, os técnicos idealizaram mais cinco circuitos que foram incluídos no calendário de 2009. Sendo sete circuitos da região de Ivaiporã e, destes, quatro pertenciam ao Vale do Ivaí.

De acordo com o calendário do projeto Caminhadas na Natureza no Paraná, divulgado no site da EMATER, foram programados 15 circuitos de caminhadas no Território Vale do Ivaí para o ano de 2015, conforme o quadro a seguir.

Quadro 1. Calendário de caminhadas na natureza do Território Vale do Ivaí em 2015

\begin{tabular}{|llll|}
\hline & Municípios & Circuitos & Datas \\
\hline 1 & Borrazópolis & Salto Fogueira & $15 / 03$ \\
2 & Barbosa Ferraz & Cachoeira do São Joaquim/Engenho Velho & $22 / 03$ \\
3 & Cambira & Pedras do Cambira & $03 / 05$ \\
4 & Lidianópolis & Porto Ubá/Rio Ivaí & $31 / 05$ \\
5 & Lunardelli & Santa Rita de Cássia & $05 / 07$ \\
6 & Apucarana & Juruba & $12 / 07$ \\
7 & Ariranha do Ivaí & Ariranha & $26 / 07$ \\
8 & Ivaiporã & Madeira & $23 / 08$ \\
9 & Corumbataí do Sul & Morros e Colinas & $30 / 08$ \\
10 & Jardim Alegre & Rota do Café & $13 / 09$ \\
11 & Godoy Moreira & Ferraduras do Corumbataí & $20 / 09$ \\
12 & Grandes Rios & Rio Ivaí & $27 / 09$ \\
13 & Faxinal & Rota das Cachoeiras & $25 / 10$ \\
14 & Apucarana & Caminhada da Lua & $28 / 11$ \\
15 & Cambira & Bela Vista Palmeirinha & $06 / 12$ \\
\hline
\end{tabular}

análise de reconstituição do processo histórico do Projeto Caminhadas na Natureza no Vale. 
Fonte: os autores, baseado em EMATER, 2015.

Os 15 circuitos estão distribuídos em 13 municípios, pois Apucarana e Cambira possuem dois circuitos de caminhada credenciados na Anda Brasil e no IVV. Segundo o relatório interno da EMATER de 2014 (último ano disponível para a análise), ocorreram, no Paraná, 122 circuitos de caminhadas em comunidades rurais, com a participação de 32 mil caminhantes.

Nesse processo de implantação das Caminhadas na Natureza, destaca-se o papel que o Estado possui, através, incialmente, do apoio financeiro do MDA e, operacionalmente, da EMATER e das prefeituras. $O$ projeto é, desde o início, entendido pelos entrevistados como uma metodologia para alcançar o desenvolvimento rural, o grande objetivo e ideal que aparece em seus discursos.

\section{Motivações dos atores para as caminhadas no Território Vale do Ivaí}

Conforme tratado acima, as caminhadas podem ser entendidas como uma modalidade de turismo rural. Mas, para se discutir as motivações dos atores para as Caminhadas na Natureza, é necessário compreender as características que diferenciam as caminhadas das demais modalidades de turismo rural.

Antes de tudo, as caminhadas exigem que os turistas estejam dispostos a praticar atividade física, mesmo sendo considerada soft (EZEQUIEL e CARVALHO, 2014). Do ponto de vista dos agricultores, deve existir uma preparação diferenciada, pois as caminhadas são eventos que necessitam de organização operacional e cumprimento de normas de segurança, que envolvem o planejamento do trajeto, da infraestrutura de apoio, das pessoas, dos serviços de alimentação, da feira, patrocínios, entre outros. Com relação aos organizadores (normalmente do poder público) é necessário planejar o apoio ao evento em geral, como divulgação, promoção, pessoas, sinalização, infraestrutura, ambulância, entre outros (ANDA BRASIL, 2007). E quanto aos agricultores, é necessário que estejam organizados para atender os caminhantes e, principalmente, prestar os serviços de alimentação para uma considerável quantidade de pessoas.

As Ciências Sociais, sobretudo a Antropologia, apresentam um debate muito interessante a respeito do ato de caminhar, que possui 
uma estreita relação com o turismo. Steil (2002) diz que uma das formas das Ciências Sociais interpretarem o turismo é sob o referencial religioso. O autor afirma que Durkheim (1989, apud STEIL, 2002) via nas "procissões do turismo moderno um ritual, celebrado em datas fixas e cumprido com o objetivo de intensificar o laço social nas sociedades contemporâneas" (STEIL, 2002, p. 53). Inspirado em Durkheim, MacCannel (1976) afirma que o turista é uma espécie de peregrino contemporâneo que, distanciado da vida cotidiana, busca autenticidade em outros lugares e outros tempos. Para esses autores, o turismo pode assumir algumas funções da religião no mundo moderno. Para Steil (2002), o bem-estar físico e saúde, atributos do corpo, são formas de se aperfeiçoar ou evoluir como seres humanos. A caminhada, o movimento do corpo, é a maneira pela qual os sujeitos entram em contato com o mundo.

Entretanto, para o estudo das Caminhadas na Natureza, não basta entender o ato de caminhar em si, o meio rural também é um elemento nesta discussão. Pois, é importante compreender os motivos que levam as pessoas percorrerem dezenas (e até centenas) de quilômetros desde sua residência até a comunidade rural. Se fosse caminhar apenas por bem-estar e saúde, uma esteira num ambiente fechado resolveria a questão.

Um estudo sobre o comportamento ao caminhar, publicado na Revista Social Science \& Medicine, em 2007, afirma que pessoas se engajam em comportamentos saudáveis por outras razões além da saúde em si, indicando a existência de significados e valores psicológicos inerentes (DARKER, LARKIN e FRENCH, 2007). Outro estudo da área das Ciências da Saúde, publicado na Revista Health \& Place, em 2013, discute a relação entre caminhar em grupo e a paisagem, analisando-a como uma técnica terapêutica para a saúde e cura (DOUGHTY, 2013). O estudo indica que o ato de caminhar em grupo promove interação social e as características do lugar contribuem significativamente para isso. A autora denomina a paisagem rural como "terapêutica", pois é capaz de promover uma terapia corporal compartilhada, o que contribui para a saúde e cura dos indivíduos. Nesse sentido, estes caminhantes entrevistados revelam sua motivação:

Além do prazer, tem a questão da saúde. Demos um jeito também de colocar os filhos nisso. Eu sou hipertenso e preciso caminhar numa frequência maior. Ter contato com pessoas de 
lugares diferentes, conhecer gente nova e formar um grupo de amigos por todo o Paraná. (Caminhante, homem, 55 anos).

Voltando às Ciências Sociais, Steil e Toniol (2011) afirmam que o caminhante não se preocupa em cultivar apenas seu bem-estar físico, mas que parece haver no ideal de saúde desses sujeitos uma forte relação entre as dimensões físicas e psíquicas. Assim, o contato com a natureza (ou com o rural) torna-se algo privilegiado na busca desse ideal. Ou seja, corpo, mente e natureza estão fortemente interrelacionados no ato de caminhar e possui resquícios religiosos, segundo sugerem Steil e Toniol (2011).

Com relação às motivações em praticar o turismo rural, existem, na literatura internacional, vários modelos e tipologias. A busca pela interpretação e classificação de motivações, de acordo com Kastenholz et al (2014, p. 44), são orientadas pela ideia seminal de que "o visitante viaja, em primeiro lugar, porque procura viver uma experiência fora do seu ambiente habitual de residência". A partir dessa ideia, os estudos sobre motivação estão fundados na Sociologia, na Psicologia Social, na Psicologia Ambiental ou na Geografia Humana.

Trazendo à luz diversos estudos, Kastenholz et al (2014, p.46) sumarizam que a principal motivação dos turistas ao praticar turismo rural é a "proximidade com a natureza", quer para atividades de lazer, recreativas, desportivas ou para o contato com a natureza em si". Isso corrobora com o discurso de Steil (2002) e Steil e Toniol (2011). É exemplo dessa motivação:

Eu cresci dentro dos esportes. Eu e meu marido andamos de bicicleta. Então tudo que é ligado a esporte e natureza eu estou dentro. Mas tem um relaxamento. Tem um momento de reunião com a família. Você vai olhando a natureza, vai olhando as flores,.. Eu queria participar de todas as caminhadas. Sabe por que? Porque eu quero conhecer todos os circuitos. Você conhece pessoas novas. Eu conheço amigos que tem depressão e que melhoram tendo contato com a natureza. Aí você chega lá e vê pessoas de 75 anos caminhando. Isso te dá uma motivação maior. A interação com outras pessoas, a interação com a natureza é muito bom. Você está caminhando, você vê um rio, você vê uma pedra, você vê uma árvore, você vê uma planta, você vê um passarinho... então a caminhada é para desestressar. Isso é importante. O ser humano hoje anda muito 
estressado. E é o momento que você pode levar o filho, de você estar caminhando com a sua família. Eu gosto bastante. (Caminhante, mulher, 46 anos).

Outra forte motivação é a busca por "relaxamento, tranquilidade, e contraste com a vida urbana", o que dialoga com a ideia de "lazer compensatório" (do esforço do trabalho), associada à saúde e bemestar. De acordo com as caminhantes:

Para mim, se tiver caminhada todo domingo, eu venho todo domingo. Eu gosto. Para mim parece que sai um fardo das costas. Chego em casa, durmo e no outro dia eu estou nova, na segunda-feira. Para mim um final de semana que não tem caminhada eu... tem trabalho, tem faculdade, é puxado. E a caminhada relaxa. Eu gosto. (Caminhante, mulher, 34 anos).

Outras motivações lembradas pelos autores são o interesse na convivência com parentes e amigos num ambiente diferente do habitual, assim como o interesse em conhecer a região, em busca de expandir conhecimento sobre paisagens, cultura, gastronomia, história, arquitetura, modo de vida rural. É exemplo:

É essa integração que a gente tem com o grupo. E você vai caminha, chega cansado fisicamente, mas a cabeça está leve. Assim é o sair, é o conhecer, é o novo... É bacana isso. Quantas pessoas eu conheci nas caminhadas... Lugares que conheci... Lugares que eu jamais imaginei ir, se não fosse a caminhada. Jamais eu iria para o interior de Santa Maria do Oeste ou de Guarapuava se não fosse a caminhada, né? E a gente tem ido na região toda. Tem conhecido a região toda, né? Isso é bacana. (Caminhante, mulher, 54 anos).

Também são motivações a busca por relações próximas e intimistas com as pessoas do rural e, ainda, a busca do turista pela nostalgia de regressar às suas origens rurais ou avivar memórias do passado. São exemplos:

Como eu disse, eu sou geógrafa ambientalista e eu nasci na comunidade rural. Eu nasci na agricultura. Meu pai é um imigrante, que veio do Japão, e a gente viveu sempre na agricultura. E eu depois de casa, nunca tirei meus pés da agricultura. É minha raiz e vou morrer. Eu tenho que prestigiar. É o meu compromisso. (Caminhante, mulher, 64 anos). 
É interessante lembrar que Kastenholz (2006) esclarece que existem diferentes tipos de turistas que visitam o rural. A demanda não é homogênea, podendo existir outros perfis motivacionais menos nítidos na pesquisa.

Grande parte dos estudos sobre motivação ao turismo rural são realizados sob o ponto de vista do turista. Entretanto, as motivações do ponto de vista dos agricultores ou dos organizadores/apoiadores são menos abordadas nos estudos disponíveis na literatura.

Assim como a ideia basilar, do ponto de vista do turista, é buscar uma experiência diferente de seu cotidiano, do ponto de vista dos agricultores, a ideia fundamental é que estes ingressam na atividade de turismo interessados no ganho financeiro. Ainda são poucos estudos, na perspectiva do desenvolvimento rural, que revelam as motivações dos agricultores para a atividade turística. Porém, estudos sobre o ingresso na atividade de agroindústrias familiares, como estratégia de diversificação econômica das propriedades, corroboram com a ideia fundamental do incremento da renda familiar como motivação principal (AGNE, 2010; CARVALHEIRO, 2010; FERRARI, 2011). É exemplo da dimensão econômica na motivação do entrevistado:

É por causa do pescador. Essa é a motivação principal. Eu quero chegar, deitar na cama, dormir sossegado e saber que eles estão legal. Em outrora, em tempos passados, a gente pegava, estava trabalhando, tinha o serviço da gente, recebendo o salário, mas o pescador passando necessidade, passando frio, de repente até faltando alimento... E eu pensava 'eu sou dessa mesma classe, vim dessa mesma origem'". Então eu acho que a gente tem que fazer alguma coisa, eu tenho que fazer alguma coisa. Então essa caminhada foi mais alguma coisa que surgiu para estar trazendo renda ao pescador, para eles não passarem tanta necessidade. Porque se deixar, se ninguém intervir nessa história, daqui a pouco os pescadores de Porto Ubá não existem mais, acabou. (Pescador, homem, 48 anos).

Mesmo tendo a dimensão econômica presente em suas falas, os agricultores demonstram que o ganho financeiro não é um fim, mas um meio de sobrevivência e reprodução social, assim como a valorização do meio rural, evidenciando um forte apelo emocional. Nesse sentido: 
A gente teve sempre a vida na área rural, né? E a gente vai com o tempo vai se distanciando dela, né? E com isso também faz que o retorno da gente é valorizar mais o setor rural. E outra coisa: ver a alegria dos outros que vem participa e conhece a gente que está aí, né? Fazer com que as pessoas se sintam bem e valorizados. E que as pessoas tenham conhecimento não só de nós aqui, mas de outros lugares. Então isso é importante. (Agricultor, homem, 67 anos).

O estudo de Souza et al (2014), a respeito do turismo rural pedagógico, apresenta resultados que indicam que a motivação dos agricultores para ingressar na atividade turística é o retorno financeiro e aumento da renda familiar, seguida da qualidade de vida e retorno pessoal. Além disso, a satisfação em trabalhar com os turistas e possibilidade de ocupação produtiva são outras motivações evidenciadas pelos entrevistados. Nesse sentido, o depoimento apresentado a seguir sugere a satisfação do contato com os caminhantes:

Estar em contato com as pessoas. Porque na área rural, a gente não tem esse movimento de pessoas. A gente se reúne uma vez por semana, mas só o pessoal do bairro. Estar mais em contato com mais gente, eu acho isso gratificante. As pessoas falando que elas gostam aqui e isso é gratificante... as pessoas falarem bem e a gente estar mostrando o que está fazendo, está divulgando. Então essa é a motivação principal. (Agricultor, homem, 51 anos).

Nesse depoimento, assim como em outros, observa-se a expressão de um sentimento de prestígio dos agricultores ao receberem os caminhantes. É exemplo o depoimento apresentado a seguir:

Eu gosto, eu gosto de estar em contato com a pessoas mesmo. Outra porque eu vejo as mudanças no meu bairro. E eu penso assim: 'eu vou morar aqui, a minha vida vai ser aqui a minha vida toda'. Eu quero, já decidi que eu quero ficar aqui. E eu não quero ficar num bairro esquecido! Um bairro que ninguém conhece! E eu quero envelhecer num bairro que, por exemplo, tenha as caminhadas que eu quero, que todos nós juntos queremos. Que tenha uma ATI (academia de ginástica ao ar livre). A gente vai envelhecer, a gente vai precisar disso. Então eu quero envelhecer num bairro conhecido. E se meus filhos no futuro quiserem voltar e morar aqui, serão muito bem-vindos. 
Mas depois da formação! Sem formação eu não aceito eles. (Agricultora, mulher, 47 anos).

Uma dimensão de motivação observada nos depoimentos dos agricultores se refere ao estreitamento de laços sociais entre a própria comunidade, que expressam valores como união e cooperação. São exemplos os depoimentos apresentados na sequência "A união do pessoal, né? Tem pessoas que estão afastadas, que não frequentam a igreja, mas na época da caminhada, as pessoas vêm para ajudar. Tem umas três famílias, que vêm para ajudar nas caminhadas, isso é muito bonito." (Agricultora, mulher, 44), "Porque meus companheiros de pesca é tudo junto. Se eles vão trabalhar eu vou também, né? E outra: quantas crianças você vê andando aí também, né? Então eu vou ajudar." (Pescador aposentado, homem, 84 anos).

Com relação aos organizadores, assim como no discurso dos caminhantes e dos agricultores, a dimensão social ou interpessoal também está presente na resposta dos organizadores das caminhadas. É exemplo disso o depoimento da técnica da EMATER:

Estar em contato com as pessoas, se envolver e ver que dá resultado. Você vê às pessoas ás vezes saindo daquele comodismo de às vezes estar naquele lugar. É gratificante você ver que as pessoas estão se movimentando, que está acontecendo. É muito bom. E que está gerando renda para eles, né? É o que buscam, né? Mesmo que seja uma vez por ano, eles estão lá trabalhando sabendo que vão ter um retorno. Daí a prefeitura se envolve, a agricultura, a saúde, vê o que está acontecendo no município. Que naquela região tem um potencial e que eles podem aproveitar isso, né? Mesmo tendo problemas, porque não é fácil organizar, mas que no final eles estão vendo um resultado. (Técnica da EMATER, mulher, 53 anos).

Nesse depoimento, a entrevistada aponta, além da dimensão social, uma dimensão econômica, quando expõe sobre as oportunidades que os municípios poderiam aproveitar ao desenvolver o potencial turístico das comunidades por meio da caminhada na natureza. Essa dimensão também está presente nos seguintes trechos de entrevistas:

A gente sempre discutia que alternativa se tem para o meio rural. A gente, enquanto técnico da EMATER, a gente tem que 
enxergar um pouco mais longe. A caminhada vai além da caminhada. A caminhada é um motivo para se buscar outras coisas para o meio rural. Então a motivação é criar alternativas para o agricultor se manter na propriedade, para melhorar a condição dele na propriedade. (Técnico da EMATER, homem, 59 anos).

Percebe-se que, por trás da preocupação em agregar valor aos produtos e gerar renda, no depoimento dos entrevistados, encontra-se presente a preocupação na melhoria das condições de vida dos agricultores. A caminhada, então, está ligada ao desenvolvimento rural, principalmente quando citam os benefícios sociais e aumento da autoestima dos agricultores como motivação para o engajamento no projeto.

Nesse sentido, nas entrevistas dos organizadores, é abordado o sentimento de prestígio e de gratificação na realização do trabalho. Essa mesma dimensão também foi observada nas entrevistas dos agricultores. Esse sentimento de prestígio aparece relacionado à divulgação dos municípios e localidades e aos elogios que recebem com relação à execução. São exemplos:

Eu gosto. Eu fui criada na roça, eu estudei, tudo, mas eu fui criada no meio rural. É uma coisa assim que me deixa muito feliz é ver as pessoas felizes. Eu acho que isso não tem dinheiro que pague. Você ver as pessoas contentes, a autoestima das pessoas, né? $\mathrm{E}$ isso me deixa muito motivada para o trabalho. E elogios, né? Que todo mundo gosta. E a gente sabe que num trabalho desse você recebe, é claro que tem as críticas, mas é para você crescer. E as pessoas vêm, falam que gostam, que é uma coisa boa. E hoje eu tenho vários amigos que eu não conheço pelo estado todo. Que eu fiz pela caminhada e me comunico por e-mail, facebook. Então isso é muito gratificante. É um trabalho que você se realiza. Você vê as comunidades felizes, você vê os caminhantes felizes, os municípios sendo divulgados e a EMATER, a empresa que eu trabalho, né? (Técnica da EMATER, mulher, 61 anos).

No depoimento anterior, a entrevistada aponta um aspecto interessante, que é a divulgação da EMATER para o público urbano, observado também em outras respostas dos organizadores. Assim como, por exemplo, no depoimento apresentado na sequência: 
É muito bom para cidade pequena. A caminhada divulga o município e a própria EMATER, que o pessoal da cidade não conhece. Eu vejo pelos meus amigos, ninguém sabe o que a EMATER faz. Ajuda a divulgar o que tem no município. Atrai gente de fora, você entendeu? Motiva o agricultor que participa. (Técnico da EMATER, homem, 29 anos).

Percebe-se, nos discursos, que a EMATER é uma empresa presente no cotidiano dos agricultores, mas que é desconhecida da população urbana. Esses discursos vão ao encontro da dimensão de prestígio, mesmo que tenha um sentido um pouco diferente dos demais discursos, mas a satisfação, reconhecimento e valorização pelo trabalho e pelo meio rural são os mesmos.

\section{Considerações finais}

As Caminhadas na Natureza estão acontecendo no Paraná e, em especial, no Território do Vale do Ivaí. Pessoas saem de suas residências aos domingos pela manhã, percorrem dezenas de quilômetros até as comunidades rurais para caminhar no espaço rural e consumir serviços de alimentação e produtos que os agricultores preparam para elas. Esse fenômeno, iniciado em 2008, é articulado e apoiado pelo Estado, por meio do trabalho de técnicos que se engajam e trabalham nos finais de semana para organizar as caminhadas. Há pertinência em entender a origem desse fenômeno, como foi o início e por que as pessoas se motivam a participar, sejam elas caminhantes, agricultores ou organizadores.

O modelo adotado pelo Paraná e, por consequência pelo Vale do Ivaí, foi adaptado do modelo europeu de esportes populares. As caminhadas foram idealizadas para atuar como estratégia de desenvolvimento rural e turismo, através do apoio a iniciativas locais das comunidades rurais. O que corrobora com o debate acadêmico internacional sobre desenvolvimento rural, multifuncionalidade e diversificação econômica.

Para compreender o processo de implantação das Caminhadas na Natureza no Vale do Ivaí, foi necessário resgatar acontecimentos que ocorreram alguns anos antes da formalização do projeto em nível federal. Os entrevistados relataram o processo de amadurecimento das 
ideias, das relações institucionais e das práticas brasileiras em outras regiões, especialmente no Estado do Rio de Janeiro, onde nasceu o projeto. Relataram também a multiplicação do projeto para outros estados, através do apoio financeiro do MDA e operacionalização, no Paraná, pela EMATER. Essa multiplicação deu-se pela realização de oficinas de capacitação para a organização de caminhadas, de acordo com o modelo do IVV. Os entrevistados revelaram que nesse processo de implantação das Caminhadas na Natureza no Território Vale do Ivaí, o papel do Estado foi e ainda é fundamental. O projeto é, desde o início, entendido, pelos entrevistados, como uma metodologia para alcançar o desenvolvimento rural. Pode-se afirmar que, por meio das caminhadas é que os entrevistados conseguiram materializar $o$ ideal de desenvolvimento rural pelo turismo.

Quanto às motivações dos atores envolvidos neste estudo de caso, revelaram-se semelhanças e diferenças nas motivações entre as categorias de entrevistados. Os caminhantes, principalmente, apresentam motivações ligadas a uma dimensão física. As referências ao relaxamento, descanso, escapar da rotina, equilibrar mente e corpo e preocupação com a saúde aparecem em seus discursos.

Nos depoimentos dos organizadores, foi percebida a dimensão econômica, pois os entrevistados citam o desejo de contribuir para o aumento da renda e melhoria das condições de vida dos agricultores. Foi também percebida uma referência ao prestígio que os municípios, localidades e até mesmo as próprias pessoas adquirem ao participar do projeto e ter seus municípios divulgados. Ao mencionarem a dimensão econômica e de prestígio, percebe-se um tom ideológico, pois a caminhada é um meio de alcançar o desenvolvimento rural, seja por meio da renda ou por meio da divulgação das comunidades. A caminhada, para eles, não é um fim em si mesma. Ela promove benefícios que não eram esperados inicialmente, como o fortalecimento das relações sociais e aumento do prestígio. Os benefícios esperados incialmente pelos organizadores eram do aumento da renda e ocupação das famílias.

Com relação às motivações dos agricultores, foi surpreendente a predominância da dimensão social ou interpessoal. Esta motivação é mais presente em seus discursos do que a dimensão econômica, ao contrário dos resultados encontrados em outros estudos. $O$ desejo de 
conhecer pessoas de outros lugares ou mesmo estreitar laços afetivos, no sentido de cooperação e união da comunidade foram as motivações dos agricultores entrevistados.

Essa dimensão social também está presente nos discursos dos caminhantes e dos organizadores, sendo, portanto, o tipo de motivação mais citado pelos entrevistados. Isso demonstra que as caminhadas são experiências co-criadas pelas pessoas, assim como defende o estudo de Kastenholz et al. (2014). A motivação dos atores para participar do projeto passa pelas relações interpessoais construídas ou fortalecidas pela caminhada. Isso evidencia que a caminhada não é apenas um ato físico ou uma atividade econômica, mas também é capaz de estabelecer novas relações e práticas sociais. Embora este estudo contribua para o conhecimento acerca do fenômeno Caminhadas na Natureza, é necessário um aprofundamento. Por fim, pode-se dizer que a experiência das Caminhadas na Natureza no Vale do Ivaí é subjetiva e coletiva e não individual.

\section{REFERÊNCIAS}

AGNE, C.L. Agroindústrias familiares e rede de relações sociais nos mercados de proximidade na Região Corede Jacuí Centro/RS. Porto Alegre, 2010. 164f. Dissertação (mestrado em Desenvolvimento Rural) Universidade Federal do Rio Grande do Sul, Faculdade de Ciências Econômicas, Programa de Pós-Graduação em Desenvolvimento Rural, Porto Alegre, 2010.

ANDA BRASIL. Projeto Caminhadas na Natureza. Silva Jardim, RJ: Anda Brasil, 2007.

(ABETA) ASSOCIAÇÃO BRASILEIRA DE EMPRESAS DE ECOTURISMO E TURISMO DE AVENTURA. Perfil do turista de aventura. 2010. Disponível em:

$<$ http://www.turismo.gov.br/sites/default/turismo/o_ministerio/public acoes/downloads_publicacoes/Turismo_de_Aventura_Versxo_Final_IMPR ESS $\times O_{-} . p d f>$.

.Acesso em: 14 nov. 2015. 
CARVALHEIRO, E.M. A construção social de mercados para os produtos da agroindústria familiar. Porto Alegre, 2010. $214 \mathrm{f}$. Tese (Doutorado em Desenvolvimento Rural) - Universidade Federal do Rio Grande do Sul, Faculdade de Ciências Econômicas, Programa de Pós-Graduação em Desenvolvimento Rural, Porto Alegre, 2010.

DARKER, C.D.; LARKIN, M.; FRENCH, D.P. An exploration of walking behavior - An interpretative phenomenological approach. Social Science \& Medicine, n. 65, p. 2172-2183, 2007.

DOUGHTY, K. Walking together: the embodied and mobile production of a therapeutic landscape. Health \& Place, n. 24, 2013 (p. 140-146).

EZEQUIEL, G.; CARVALHO, M. O turismo de natureza como potenciador das singularidades territoriais: o caso do pedestrianismo em Portugal. In:

CRISTOVÃO, A. et al (orgs.) Turismo Rural em Tempos de Novas Ruralidades. Porto Alegre: Ed. da UFRGS, 2014. (p. 80-94).

FAWCET, G. The International Federation of Popular Sports.2015. Disponível em: <http://www.ivv-web.org/pages/en/pdf/The-IVV-AnOverview.pdf $>$. Acesso em: 15 nov. 2015.

FERRARI, D.L. Cadeias alimentares curtas: a construção social de mercados de qualidade pelos agricultores familiares em Santa Catarina. 2011 . 345f. Tese (Doutorado em Desenvolvimento Rural) - Universidade Federal do Rio Grande do Sul, Faculdade de Ciências Econômicas, Programa de Pós-Graduação em Desenvolvimento Rural, Porto Alegre, 2011.

FIGUEIREDO, E.; EUSÉBIO, C. A experiência vivida e cocriada pela população local. In: KASTENHOLZ, E. et al. Reinventar o Turismo Rural em Portugal: cocriação de experiências turísticas sustentáveis. Aveiro: UA Editora, 2014.

FUENTES LLANILLO, R.; DEL GROSSI, M.E.; SANTOS, F.O.; MUNHOS, P.D. Regionalização Agrária do Estado do Paraná. In: Encontro de Economia 
paranaense, 2002, Maringá. I ECOPAR. Maringá: UEM, 2002. V Cd-rom. Disponível em:

<http://www.iapar.br/arquivos/File/zip_pdf/Ase/regio_agraria.pdf >. Acesso em: 21 de jul. 2014.

INSTITUTO BRASILEIRO DE GEOGRAFIA E ESTATÍSTICA. Censo da população 2010. Disponível em: <http:// www.ibge.gov.br.> Acesso em : 13 jul. 2015.

INSTITUTO PARANAENSE DE ASSISTÊNCIA TÉCNICA E EXTENSÃO RURAL (EMATER-PR). Relatório 2014 do Projeto "Caminhadas na Natureza no Paraná". Curitiba: EMATER-PR, 2014. (Documento Interno).

INSTITUTO PARANAENSE DE ASSISTÊNCIA TÉCNICA E EXTENSÃO RURAL (EMATER-PR). Calendário 2015 do Projeto Caminhadas na Natureza no Paraná. Disponível em:

$<$ http://www.emater.pr.gov.br/modules/conteudo/conteudo.php?conte udo=239> Acesso em: 15 nov. 2015.

IRCOD. Qui sommes-nous? Disponível em: <http://www.ircod.org/quisommes-nous $>$. Acesso em: $1^{\circ}$ jan. 2016.

IVV. The IVV: one overview. Disponível em: <http://www.ivvweb.org/pages/en/pdf/The-IVV-An-Overview.pdf>. Acesso em: 25 jul. 2015.

KAGEYAMA, A.A. Desenvolvimento rural: conceitos e aplicação ao caso brasileiro. Porto Alegre: Ed. da UFRGS, 2008.

KASTENHOLZ et al. A experiência turística no espaço rural. In: KASTENHOLZ et al. Reinventar o turismo rural em Portugal: cocriação de experiências turísticas sustentáveis. Aveiro: UA Editora, p. 43-50, 2014.

KASTENHOLZ, E. A segmentação de mercado como ferramenta estratégica no desenvolvimento do turismo rural. In: ALMEIDA, J.A.; SOUSA, M. de. (orgs.) Turismo rural: patrimônio, cultura e legislação. $1^{\text {a }}$ ed. Santa Maria: FACOS/UFSM, p.137-152, 2006. 
KOUCHNER, F.; LYARD, J.P. Developing walking holidays in rural areas: guide how to design and implement a walking holiday project. "Rural Inovation" Dossier n.12. Bruxelles: LEADER European Observatory, 2001. Disponível em: $<$ http://superdoc.aeidl.eu/modules/webportal/results.php?op=classem ent\&idclassement $=182 \&$ idbase $=8 \&$ search $\_$mode $=s d p>$. Acesso em: 13 nov. 2015.

LANE, B. Turismo Rural de Segunda Geração: prioridades e questões de pesquisa. In: CRISTOVÃO, A. et al (orgs.) Turismo Rural em Tempos de Novas Ruralidades. Porto Alegre: Ed. da UFRGS, p. 15-48, 2014.

MACCANNEL, D. The tourist: a new theory of the leisure class. New York: Schocken Book, 1976.

MCINTOSH, R.W.; GOELDNER, C.R.; RITCHIE, J.R. Tourism: Principles, Practices, Philosophies. Chichester: John Willey, 1995.

RODRIGUES, A.B. Turismo rural no Brasil: ensaio de uma tipologia. In: ALMEIDA, J.A.; RIEDL, M. (orgs.) Turismo rural: ecologia, lazer e desenvolvimento. Bauru, SP: EDUSC, 2000.

SECRETARIA DE ESTADO DA AGRICULTURA E ABASTECIMENTO (SEAB). Caminhadas na Natureza no Paraná: Relatório 2008. Curitiba: DEAGRO/SEAB, 2008.

SOUZA, C.; QUANDT, Q. Metodologia de Análise de Redes Sociais. In: DUARTE, F.; SOUZA, C.; QUANDT, Q. O Tempo das Redes. São Paulo: Editora Perspectiva, p.31-64, 2008.

SOUZA, M.; KLEIN, A.L.; STIGLIANO, B.V.; ELESBÃO, I.; SILVA, M. A. C. da; LEMOS, R.M de. $O$ turismo rural pedagógico sob o viés da multifuncionalidade na agricultura familiar. Análise a partir de três experiências desenvolvidas nos estados de Santa Catarina, Distrito Federal e São Paulo: relatório final de pesquisa. Porto Alegre: FACOSUFSM, 2014. 
STEIL, C.A. O turismo como objeto de estudo das ciências sociais. In: RIEDL, M.; ALMEIDA, J.A.; VIANA. A.L.B. (orgs.) Turismo rural: tendências e sustentabilidade. Santa Cruz do Sul: EDUNISC, p. 51-80, 2002.

STEIL, C.A.; TONIOL, R. Ecologia, corpo e espiritualidade: uma etnografia das experiências de caminhada ecológica de um grupo de ecoturistas. Caderno CRH. vol. 24, n. 61. Salvador, p. 29-49, jan/abr 2011 (). TULIK, O. Turismo e desenvolvimento no espaço rural: abordagens conceituais e tipologias. In: SANTOS, E. de O.; SOUZA, M. de. (orgs.) Teoria e prática do Turismo no Espaço Rural. Barueri, SP: Manole, p. 222, 2010.

TULIK, O. Turismo rural. São Paulo: Aleph, 2003. (Coleção ABC do Turismo)

WANDERLEY, M. de N.B. O mundo rural como um espaço de vida: reflexões sobre a propriedade da terra, agricultura familiar e ruralidade. Porto Alegre: Ed. da UFRGS, 2009.

Submetido em $30 / 05 / 2016$

Aprovado em 20/08/2016

\section{Sobre os Autores}

\section{Clarice Bastarz}

Doutoranda do Programa de Pós-graduação em Desenvolvimento Rural da UFRGS; Professora Assistente do Curso de Gestão de Turismo da UFSM

E-mail: clariceufsm@gmail.com

\section{Marcelino de Souza}

Doutor em Engenharia Agrícola pela UNICAMP; Professor Associado do Departamento de Economia e Relações Internacionais e dos Programas de Pós-Graduação em Desenvolvimento Rural e de Agronegócio da Universidade Federal do Rio Grande do Sul E-mail: marcelino.souza@uol.com.br 